\title{
Comparison of the diagnostic accuracy of cell block with cytology smear in serous effusions
}

\author{
Bista $\mathrm{P}^{1}$ \\ ${ }^{1}$ Department of Pathology, National Academy of Medical Sciences, Bir Hospital, Kathmandu, Nepal.
}

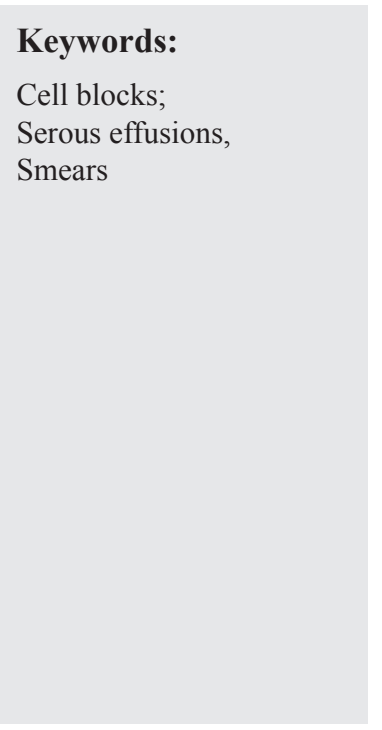

\begin{abstract}
Background: Differentiation between benign and malignant serous effusions always poses a great diagnostic dilemma. Differentiation often requires clinical findings, morphological evaluation and sometimes immunocytochemistry. Diagnostic possibility is enhanced if cell blocks are made along with the conventional cytology smears. This will help the clinicians in both treating the patient and determining the outcome of the disease process.
\end{abstract}

Materials and methods: This hospital-based cross sectional analytical study was carried out in Department of Pathology in National Academy of Medical Sciences, Bir Hospital for one year. The objective of this study was to compare the smears cytology with cell blocks sections in serous effusions.

Results: The four criteria scored for each technique were volume of background blood, amount of diagnostic cellular material, degree of cellular degeneration and trauma and architectural preservation. Background blood, amount of diagnostic material present and retention of architecture was more in cell block sections compared with smears cytology; whereas cellular degeneration and trauma was less appreciated in cell block sections which scored more than the smears cytology.

Conclusion: Cell block preparation is simple, rapid and inexpensive technique for serous fluids in which malignant cells can be reliably detected thus avoiding unnecessary invasive procedure in patient management.

\section{INTRODUCTION}

Diagnostic cytology is the science of interpretation of cells that are exfoliated from the epithelial surfaces or removed from various tissues. The advantages are it is non-invasive, simple and helps in faster reporting and is relatively inexpensive.

Getting adequate exfoliated cells in serous fluids is not

\section{Correspondence:}

Dr. Pratibha Bista, $M D$

Department of Pathology, National Academy of Medical Sciences,

Bir Hospital, Kathmandu, Nepal.

E-mail:pratibhabista@hotmail.com an easy task and diagnosis is in dilemma which not only hampers patient's outcome but also confuses pathologists. Thus, the most challenging aspect of a pathologist's work is to reliably distinguish between benign and malignant lesions in serous effusion. ${ }^{1}$ Detection of malignant cells in serous effusion is possible in nearly $40-60 \%$ of patients. Owing to the scarcity of tumor cells in malignant effusions and morphologic similarities to reactive mesothelial cells, cytological examination fails to detect malignant cells in approximately $40 \%$ of effusions.

The rate of diagnostically equivocal effusions in routine cytology is dependent on the effusion examined, type 
of preparation and staining, experience of the examiner, clinical history and application of ancillary methods. ${ }^{2,3}$

This study was carried out to analyze cytological features in smears and cell block (CB) preparations in different benign and malignant lesions causing effusions.

\section{MATERIALS AND METHODS}

This was hospital-based cross sectional analytical study carried out in department of pathology in National Academy of Medical Sciences, Bir Hospital for a total duration of 12 months from November 2010 to October 2011. All the relevant clinical and radiological data were obtained. $40 \mathrm{ml}$ of serous effusions fluid were collected in a clean container that had $4 \mathrm{ml}$ of $3.8 \%$ sodium citrate as an anticoagulant. 2-3 drops $1 \%$ glacial acetic acid was added to the fluid which ensured lysis of red blood cells. This was followed by the macroscopic examination of effusion fluid for physical characteristics. The specimen were then divided into two equal halves, $20 \mathrm{ml}$ each and kept separately.

For the smear, $20 \mathrm{ml}$ of serous fluids was centrifuged at 1500 rpm for 15 minutes and smears were made from the cell button on labeled glass slides. For PAP stain the slides were fixed immediately in absolutely alcohol whereas slides were air dried for Giemsa stain. The remaining $20 \mathrm{ml}$ of serous fluids was fixed in 1:1 solution of $10 \%$ alcohol; formalin for one hour. Then the specimen was centrifuged at $2500 \mathrm{rpm}$ for 10-15 minutes. The sediment was processed routinely in histopathology laboratory. All the samples were subjected to smear cytology and $\mathrm{CB}$ examination accordingly to the methodology described and scored per the scoring system by Thapar M et al. ${ }^{1}$

After assigning the appropriate scores, the cases were divided into 3 categories, which consisted of "diagnostically superior" (score 6-9), "diagnostically adequate" (score 3-5), "diagnostically unsuitable" (score 0-2).

Final data was entered and tabulated in Microsoft Excel Enterprise and subjected to Point Allocation Scoring System after which statistical tests were applied. The Kappa test was used when appropriate for the statistical analysis. $P$ value was calculated under the predetermined level of significance (0.05).

\section{RESULTS}

A total of 37 cases were enrolled in this study out of which19 were female and 18 male with female to male ratio of 1.17: 1 . The age ranged from 18-85 years. Out of 37 cases 10 cases $(27 \%)$ were diagnostically unsuitable. In remaining 27 cases both cell blocks and smears were. Three cases $(8 \%)$ were malignant in both the techniques but the morphology was superior in $\mathrm{CB}$ preparation. One case $(2.7 \%)$ was an inflammatory and remaining 23 cases
Table 1: Background blood in smears and cell blocks

\begin{tabular}{ccccc}
\hline Scores & Cell Blocks & N & Smears & N \\
\hline 2 & $62.2 \%$ & 23 & $43.2 \%$ & 16 \\
1 & $35.1 \%$ & 13 & $54.1 \%$ & 20 \\
0 & $2.7 \%$ & 1 & $2.7 \%$ & 1
\end{tabular}

Table 2: The amount of diagnostic material present in smears and cell blocks

\begin{tabular}{ccccc}
\hline Scores & Cell blocks & N & Smears & N \\
\hline 2 & $56.8 \%$ & 21 & $29.7 \%$ & 11 \\
1 & $13.5 \%$ & 5 & $35.15 \%$ & 13 \\
0 & $29.7 \%$ & 11 & $35.15 \%$ & 13 \\
\hline
\end{tabular}

Table 3: Degree of cellular degeneration and trauma present in smears and cell blocks

\begin{tabular}{ccccc}
\hline Scores & Cell blocks & N & Smears & N \\
\hline 2 & $56.8 \%$ & 21 & $18.9 \%$ & 7 \\
1 & $18.9 \%$ & 7 & $56.8 \%$ & 21 \\
0 & $24.3 \%$ & 9 & $24.3 \%$ & 9
\end{tabular}

Table 4: Retention of appropriate architecture and cellular architecture in smears and cell blocks

\begin{tabular}{ccccc}
\hline Scores & Cell blocks & N & Smears & N \\
\hline 1 & $56.8 \%$ & 21 & $10.8 \%$ & 4 \\
2 & $13.5 \%$ & 5 & $43.2 \%$ & 16 \\
3 & $29.5 \%$ & 11 & $45.7 \%$ & 17
\end{tabular}

Table 5: Total and mean scores for all smears and cell blocks

\begin{tabular}{lccc}
\hline \multicolumn{1}{c}{ Criteria } & \multicolumn{2}{c}{ Mean \pm SD } & P Value \\
\hline Blood obscuring $(\mathrm{n}=37)$ & Smears & Cell blocks & \\
& $1.40 \pm 0.55$ & $1.60 \pm 0.55$ & 0.017 \\
$\begin{array}{l}\text { Diagnostic material present } \\
(\mathrm{n}=37)\end{array}$ & $0.94 \pm 0.86$ & $1.27 \pm 0.90$ & 0.002 \\
\hline $\begin{array}{l}\text { Cellular degeneration } \\
(\mathrm{n}=37)\end{array}$ & $0.94 \pm 0.85$ & $1.32 \pm 0.67$ & $<0.001$ \\
$\begin{array}{l}\text { Architectural preservation } \\
\text { Arch }\end{array}$ & $1.64 \pm 0.67$ & $2.27 \pm 0.67$ & $<0.001$
\end{tabular}

$(62.16 \%)$ were reactive serous effusion. Eleven cases were of reactive pleural effusion and 12 were peritoneal effusion.

When adequacy for diagnosis was assessed for both techniques, there were more diagnostically superior smears i.e (score 6-9), obtained by cell blocks ( 25 cases) as compared to smears (16 cases).

Smears which were adequate for diagnosis (Score 3-5) were more in smears cytology techniques (13 cases) than cell blocks ( 3 cases) and the cases which did not have diagnostically adequate material were equal (8 cases) in 

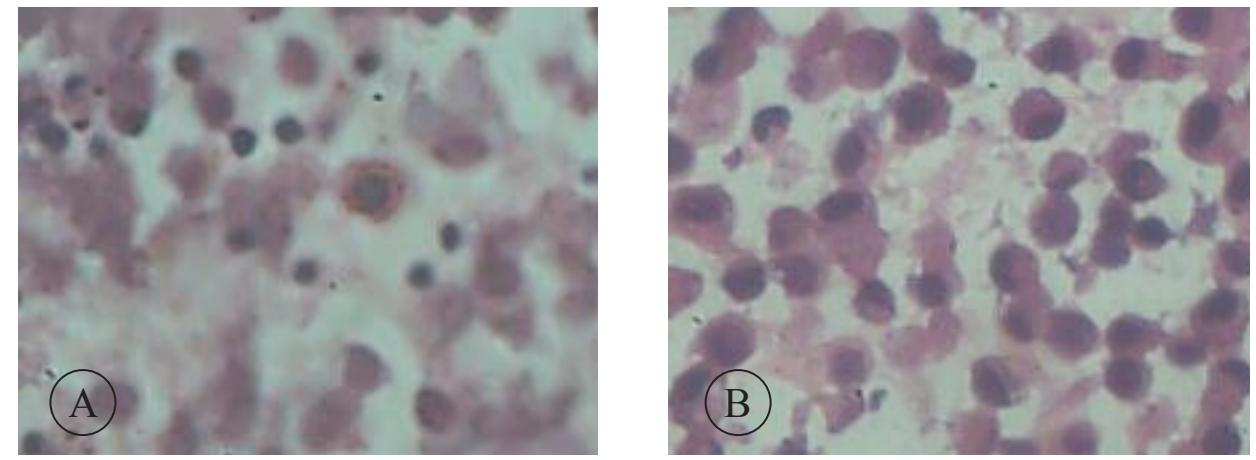

Photomicrographs 1: Reactive serous effusion (Pap stain X 40). A.Smear showing mesothelial cells arranged singly. B. Cell block sections showing mesothelial cells with better cellular morphology and clean background.
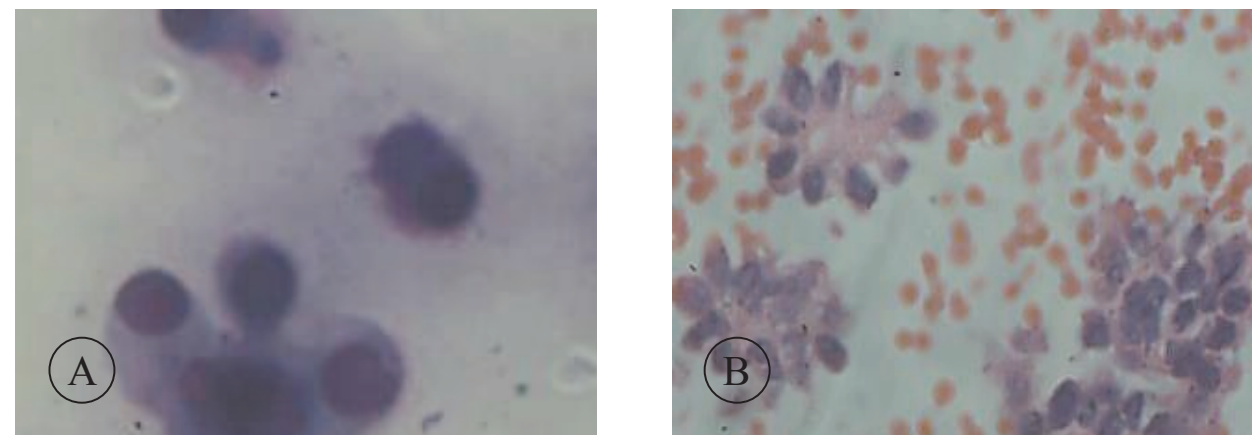

Photomicrographs 2: Metastatic adenocarcinoma (Pap stain, x40). A. Smear showing few cell balls of atypical cells displaying poor morphological details. B. Cell block section with better architectural and cytological detail showing cellular pleomorphism and hyperchromatism.

both the techniques.

Out of 37 total cases, 3 cases were malignant i.e. adenocarcinoma $(8 \%)$ in both techniques, 23 cases $(63.16 \%)$ reactive serous effusion and 1 case $(2.7 \%)$ was an inflammatory.

\section{DISCUSSION}

In this study we were only able to categorize thirty seven cases into reactive and malignant effusions and unable to further break down the reactive effusions into subcategories like tubercular, congestive heart failure, viral infection and bacterial infection etc as done by Thapar $\mathrm{M}$ et al. ${ }^{1}$ This is due to our antiquated record-keeping and not using the SNOMED code. Usage of the code would make the statistical analysis of the disease pattern much easier.

Three cases were metastatic adenocarcinoma, twenty three cases were of reactive serous effusion, one was an abscess and ten were categories as unsuitable. The low depiction of cancer in effusion in our study was attributed to our being a general hospital treating mainly non-cancerous patients.

The body fluids in our study were peritoneal and pleural fluids. There were no pericardial aspirates in our study.

The most common cause of a malignant effusion was metastatic adenocarcinoma. This was as expected since the majority of human cancers are adenocarcinomas. ${ }^{4}$ So, the serous fluids harbor adenocarcinoma more than other malignancy.

Out of 37 cases 10 cases were diagnostically unsuitable $(27 \%)$. They scored 1 on both cytology smears and cell blocks. Three cases $(8 \%)$ were malignant in both the techniques but the morphology was superior in cell blocks. Two of these were pleural fluid and one was peritoneal fluid. The two pleural fluid scored 6 and 6 in cytology smears and 9 and 8 in cell blocks respectively. One case of peritoneal fluid scored 8 in smears and 9 in cellblocks respectively. One case of pleural fluid was an abscess comprising $2.7 \%$ and remaining 23 cases including both pleural and peritoneal (62.16\%) were reactive serous effusions. Pleural fluid comprised 11 cases and peritoneal fluid comprised 12 cases of reactive serous effusions.

Effusions in cancer patients are not always "malignant" but may be reactive and of transudative type. In cancer cachexia, hypoproteinemia due to cancer associated malnutrition, external pressure on vascular or lymphatic channels or the effusion may be exudative due to concomitant inflammatory disease. In these cases we will not get cancer cells in the body fluids. In the study by Thapar $\mathrm{M}$ et al. ${ }^{1}$ there were seventy cases of cancer with effusions. Out of 70 cases studied, diagnosis was made by histopathology in 58 cases i.e. $82.8 \%$ and by fine needle aspiration cytology (FNAC) in 
12 cases i.e. $17.2 \%$. Peritoneal fluid was obtained in 38 cases i.e. $54.25 \%$, pleural fluid in 30 cases comprising $42.85 \%$ and pericardial fluid in two cases i.e. $2.87 \%$ for smear examination and cell blocks preparation. Yet smear yielded cancer cells in only 50 cases and cell blocked furthered increased the diagnostic yield and showed positivity in 60 cases.

In our study the age of the patients who has body effusions ranged from the age of 18 to 86 years. This was similar to the age range in the study done by Davidson $\mathrm{B}$ et al..$^{5}$ The majority of the patients were in the fifth and sixth decades of life. The male: female ratio of the studied patients was 1.17:1.0 but we have to heed the fact that ours is a nongynaecological hospital. So this ratio will not represent the true male: female ratio in the serving population as ovarian tumors are the leading cause of body fluid effusions in the female worldwide.

The minimum amount of serous fluid requested was $40 \mathrm{ml}$ for our study but in one instance $20 \mathrm{ml}$ of serous fluid was submitted for examination. Malignant cells were detected in the smears cytology as well as cell block preparation. This is also in concurrence to the findings of Buckley $\mathrm{O}$ et al. ${ }^{2}$

Reactive mesothelial cells in form of cell balls can easily mimic adenocarcinoma. The tell-tale sign which gives insight into the benign nature is the intercellular window with hair - like bridges connecting the neighbouring cells. ${ }^{6}$

The morphological evaluation of cytological specimens from body cavity fluids faces difficulties in the differential diagnosis between benign reactive mesothelial cells and adenocarcinoma or malignant mesothelioma. So, different antibodies serve as reliable markers in the differential diagnosis of reactive mesothelial cells, adenocarcinona and malignant mesothelioma in serous effusions..$^{7-14}$

This diagnostic dilemma can be furthered settled by staining with PAS stain, D-PAS, Alcian blue and Hyranuronidase alcian blue. Introduction of CK 5/6 and calretinin helps in differentiating mesothelioma from adenocarcinoma. ${ }^{6,9,10,14,15}$

According to the point scoring system of Thapar $\mathrm{M}$ et al four different criteria were used and score given was from 0 to $2 .{ }^{1}$

For all the 37 cases included in this study diagnosis was assigned by smears cytology and cell blocks in all 27 cases. 10 cases were diagnostically unsuitable $(27 \%)$. Out of these ten unsuitable cases, there were 6 pleural fluids and 4 peritoneal fluids. Three cases $(8.1 \%)$ were malignant i.e. two cases were pleural fluid and one was peritoneal fluid. The two positive cases were metastatic adenocarcinoma in both the techniques but the morphology was superior in cell blocks preparations which provided better architectural details in the form of better delineation of cells balls, papillae, three dimensional clusters, excellent nuclear and cytoplasmic details and individual cell characteristics. ${ }^{1,4,8}$

In this study, $10 \%$ alcohol and formalin in 1:1 ratio were used for fixation of serous fluids. ${ }^{1}$ Cell blocks were prepared by using paraffin wax in this study. They display good morphological details. Cotton block method is another alternative by which cytomorphological features in body fluids can be studied. ${ }^{11,15-17}$

In this study, all three malignancies found in the smears and blocks were adenocarcinomas. This comprised $8.1 \%$ of cases (3/37). This is in concurrence to other studies which showed adenocarcinoma as the principal malignancy in body fluids. Of the three malignancies in our study, two had a possibility of having their primary lesion in lungs. $18 \mathrm{We}$ got only one bronchial biopsy specimen which turned out to be adenocracinoma. In our study there were just three cases of malignancy and this constitutes too small a size for accurate statistical analysis.

Several studies have shown that repeat evaluation of serous effusion that is aspirated for therapeutic purpose also increases the diagnostic accuracy. ${ }^{1,18}$

In the study of Thapar $\mathrm{M}$ et al the diagnostic yield was increased by both smears cytology and cell blocks with the examination of additional specimens. ${ }^{1}$ When they first evaluated the serous fluid from patients who had histologically proved primary lung tumors, the percentage they obtained were $43.75 \%$ and $56.25 \%$ in smears and cell blocks respectively. When subsequent samples were evaluated in the same patients, their diagnosis increased to $62.5 \%$ and $75 \%$ in smears and cell block respectively. The increase in percentage of was also appreciated in patients who had histologically proven ovarian malignancy. Since our hospital does not cater to gynaecology ward we do not have access to ovarian tumours and so not a single case of ovarian malignancy was recorded in the present study.

Considering the increase in diagnosis of malignancy in subsequent specimens we should make provision of further follow up in cases of serous effusions and processing of subsequent samples whenever they are aspirated to enhance the diagnostic accuracy. In the study by Thapar $\mathrm{M}$ et al subsequent smears and cell blocks from further aspirates enhanced the diagnostic yield of malignancy in both these modalities. ${ }^{1}$

In our study there were two cases of repeat aspirates but both the first and the subsequent aspirates did not reveal the presence of malignant cells in them.

There was not a single case of mesothelioma in our study. In the study by Thapar $\mathrm{M}$ et al there were two cases of mesothelioma and they were detected by smears as well as blocks in the initial evaluation. ${ }^{1}$

Some samples were acellular both in smears and cell blocks. 
They showed exudative background only in spite of taking all precaution while processing them. This is possibly attributed to the content that is present in the fluid, most likely proteinaceous material.

Taking into consideration the advantages stated above, we recommend the practice of processing of body fluid to cell blocks routinely to augment the information that is obtained solely from smear cytology of body fluids. These two modalities for body fluid are synergistic and the diagnostic information they yield will be cumulative.

\section{CONCLUSION}

Cell blocks provides better architectural display, good yield of diagnostic material from serous effusions with minimal degenerative changes. It proves to be a better alternative to conventional smear. Findings of both the cell blocks and smears will complement each other to come to a definite diagnosis.

\section{REFERENCES}

1. Thapar M, Mishra RK, Sharma A, Goyal V. Critical analysis of cell block versus smear examination in effusions. J Cytol 2009;26:60-4.

2. Buckley O. Thoracocentesis for Potential Malignancy: Does Volume Matter? J HK Coll Radiol 2008;11:72-5.

3. Sallach SM, Sallach JA, Vasquez E, Schultz L, Kvale P. Volume of pleural fluid required for diagnosis of pleural malignancy. CHEST 2002;122:1913-7.

4. Churg A, Colby TV, Cagle P, Corson J, Gibbs AR, Gilks B, et al. The separation of benign and malignant mesothelial proliferations. Am J Surg Pathol 2000;24:1183-200.

5. Davidson B, Nesland J, Risberg B, Kopolovic J. Expression of Membrane-Type 1, 2, and 3 Matrix Metalloproteinases Messenger RNA in Ovarian Carcinoma Cells in Serous Effusions. Anatomic Pathology 2011;115:517-24.
6. Ardengh JC, Lopes CV, de Lima LF et al. Cell block technique and cytological smears for the differential diagnosis of pancreatic neoplasms after endosonography-guided fine-needle aspiration. Acta Gastroenterol Latinoam 2008;38:246-51.

7. Boudreaux VL, Mody DR, Zhai J, Donna C. Cytologic Malignancy Versus Benignancy: How useful are the "Newer" markers in body fluid cytology. Arch Pathol Lab Med 2008;132:23-8.

8. Khan N, Sherwani R, Afroz N, Kapoor S. Cytodiagnosis of malignant effusion and determination of primary site. Journal of Cytology 2005;22:107-10.

9. Ueda J, Iwata T, Ono M, Takahashi M. Comparison of three cytologic preparation methods and immunocytochemistries to distinguish adenocarcinoma cells from reactive mesothelial cells in serous effusion. Diagn Cytopathol 2006;34:6-10.

10. Gong Y. Immunocytochemistry of Serous Effusion Specimens: A Comparison of ThinPrep vs. Cell Block. Diagn Cytopathol 2003;28:1-5.

11. Mayall F, Chang B, Darlington A. A review of 50 consecutive cytology cell block preparations in a large general hospital. J Clin Pathol 1997;50:985-90.

12. Politi E, Kandaraki C, Apostolopoulou C, Kyritsi T, Koutselini H. Immunocytochemical panel for distinguishing between carcinoma and reactive mesothelial cells in body cavity fluids. Diagn Cytopathol 2005;32:151-5.

13. Mezger J, Permanetter W, Gerbes AL, Wilmanns W, Lamerz R. Tumour associated antigens in diagnosis of serous effusions. J Clin Pathol 1988;4:633-43.

14. Nguyen G. Cytopathology of Pleural Mesotheliomas. Am J Clin Pathol 2000;114:68-81.

15. Mohanty S, Dey P. Serous effusions: diagnosis of malignancy beyond cytomorphology. An analytic review. Postgrad Med 2003;79:569-74.

16. Su XY, Li GD, Liu WP, Xie B, Jiang YH. Cytological differential diagnosis among adenocarcinoma, epithelial mesothelioma, and reactive mesothelialcells in serous effusions by immunocytochemistry. Diagn Cytopathol 2011;39:900-8.

17. Ringenberg QS, Doll DC, Loy TS, Yarbro JW. Malignant ascites of unknown origin. Cancer 1989;64:753-5.

18. Monte SA, Ehya H, Lang WR. Positive effusion cytology as the initial presentation of malignancy. Acta Cytol 1987;31:448-52. 